\title{
ATUAÇÃO JURÍDICA E MUDANÇA DE PARADIGMA
}

\author{
Adamo Perrucci ${ }^{402}$ \\ Recebido em: 30/11/2016 \\ Avaliado em: 30/12/2016
}

\begin{abstract}
RESUMO
Nas páginas seguintes visa-se encarar a questão da atuação do jurista numa sociedade complexa e em constante mutação, onde a força normativa da Constituição é desafiada pelas desigualdades e pela inefetividade dos direitos fundamentais. Se por um lado, o profissional do direito não tem como ignorar a exigência de um conhecimento adequado das leis e das técnicas de sua aplicação, por outro lado, tornase indispensável pensar modos concretos de se habilitar o jurista do amanhã para uma atuação que responda eficazmente aos desafios de um mundo extremamente conflituoso. Neste sentido, objetiva-se perguntar pelo modo de se favorecer o desenvolvimento crítico da consciência do operador forense para que ele possa satisfazer as expectativas de justiça do meio social em que opera.
\end{abstract}

Palavras-chave: Constituição. Atuação jurídica. Sociedade. Ciência jurídica.

\section{INTRODUÇÃO}

Pode o direito ser impermeável às mutações sócio-político-culturais do contexto em que atua? É ainda sustentável a ideia de que o direito ocupa um lugar equidistante às situações conflitivas da sociedade, posicionando-se como agente neutro capaz de proporcionar soluções universalmente justas? Existe uma relação entre a operatividade jurídica e os anseios sociais e humanos por justiça?

Tais interrogações representam o ponto de partida para se repensar a natureza e a função do direito numa época caracterizada por constantes mudanças e que exige uma atuação jurídica que assegure o exercício dos direitos sociais e individuais. É mister reconsiderar a fonte de

\footnotetext{
${ }^{402}$ Pós-doutor pela Universidade Federal do Rio Grande do Norte. Doutor em Filosofia e História da Filosofia pela Università degli Studi di Bari. Mestre em Teologia pela Pontificia Università Gregoriana. Graduado em Filosofia pela Università degli Studi di Bari. Graduado em Teologia pela Pontificia Facoltà Teologica dell'Italia Meridionale. Atualmente é Professor visitante adjunto da Universidade Federal do Rio Grande do Norte.
} 
legitimidade do universo jurídico para se compreender sua identidade no Estado democrático de direito e, por conseguinte, se favorecer uma reflexão crítico-problemática acerca do alicerce epistemológico da ciência jurídica atual.

A referida problematização tem como objetivo trazer à tona a emergência de um novo paradigma teórico-operacional em que deveria se pautar o agir jurídico hodierno, como modo de se garantir para o profissional forense um maior atrelamento de sua atuação às demandas sócio-políticas realmente relevantes.

Destarte, cabe-nos investigar previamente o papel que o direito exerce nesta nova legalidade brasileira e quais são os pressupostos teóricos para o jurista atuar de forma adequada à missão que a Carta Maior lhe confiou. Incumbidos de realizar uma legalidade de forte conteúdo social e político, os juristas se tornam depositários de expectativas de transformação do meio em que eles operam, o que exige uma superação do mero legalismo/normativismo quanto ao modo de interpretação e aplicação do direito. Pretende-se saber então até que ponto o referido questionamento do perfil e do papel do jurista vira um modo concreto de se viabilizar a implementação dos valores constitucionais.

Para usarmos as palavras de um eminente estudioso,

Como processo de adaptação social, o direito deve estar sempre se refazendo, em face da mobilidade social. A necessidade de ordem, paz, segurança, justiça, que o direito visa a atender, exige procedimentos sempre novos. Se o direito se envelhecer, deixa de ser um processo de adaptação, pois passa a não exercer a função para qual foi criado. $^{403}$

É neste contexto que precisamos discutir a crise do Direito a partir do esgotamento do modelo liberal-individualista-normativista que se mostra inadequado para atender as múltiplas demandas de uma sociedade complexa e conflituosa, marcada pelo crescimento exponencial de direitos transindividuais que reclamam novas competências dos operadores forenses. Conforme salientado por Lenio Streck,

Essa crise ocorre porque o velho modelo de Direito (de feição liberal-individualistanormativista) não morreu e o novo modelo (forjado a partir do Estado Democrático de Direito) não nasceu ainda. Deixar vir o novo à presença: esse é o desafio. ${ }^{404}$

\footnotetext{
${ }^{403}$ NADER, Paulo. Introdução à Ciência do Direito. 29. ed. Rio de Janeiro: Freitas Bastos, 1989. p. 23.

404 STRECK, Lenio Luiz. Jurisdição Constitucional e Hermenêutica: Perspectivas e Possibilidades de Concretização dos Direitos Fundamentais-Sociais no Brasil. Novos Estudos Jurídicos, v. 8, II, 2003, p. $257-301$.
} 
Isso altera o desempenho e a função social do jurista e impõe um sério questionamento de seu modo de atuação num contexto em que a extensa massificação social torna ainda mais evidente a discrepância entre Constituição e sociedade.

\section{O DIREITO FACE AOS NOVOS DESAFIOS}

O direito, por ser um fenômeno histórico-cultural, apresenta os traços de uma criação sujeita a transformações que andam de mãos dadas com a coletividade na qual ele atua. A crescente complexidade diante da qual ele vem sendo posto na época presente, caracterizada pelo surgimento dos assim chamados direitos de nova geração, reclama novas competências dos profissionais do direito, em termos de aberta problematização e investigação a respeito do lugar que as referidas conquistas ocupam na nova legalidade brasileira pós-88.

Neste novo horizonte político-cultural, é possível afirmar que

[...] o futuro do direito parece se projetar mesmo na direção de uma dimensão públicatransindividual. A emergência em profusão dos direitos difusos, coletivos e sociais, no final do século XX e início do século XXIé a prova mais evidente de que o direito [...] caminha hoje, a passos largos, para a sua decidida publicização. ${ }^{405}$

A peculiaridade da atual realidade social exige um esforço de sintonização com as dinâmicas transformadoras que perpassam o meio em que o profissional do direito atua. Tratase de uma realidade que prova a insuficiência de uma abordagem monodisciplinar, assentada num conhecimento supostamente objetivo e liberto de qualquer relatividade cultural que possa prejudicar a sua eficácia operacional. Na verdade, o desejável é um conhecimento que leve a sério a complexidade semântica evocada pela cultura dos novos direitos que requer, pelo contrário, uma abordagem interdisciplinar como modo de analisar adequadamente problemáticas referentes à globalização da cidadania, dos direitos humanos junto com a questão da efetivação da justiça.

Frente a uma sociedade que almeja ver concretizados os valores constitucionais, o Direito não tem como fugir do papel de construtor de um autêntico Estado Democrático Constitucional, com forte conotação axiológica.

Esta incontestável dimensão pública e transindividual que o Direito vem adquirindo deve-se a uma renovada consciência a respeito da necessária assunção de um compromisso

${ }^{405}$ MACHADO, Antônio Alberto. Ensino jurídico e mudança social. 2 ed. São Paulo: Atlas, 2008, p. 110. 
eminentemente ético por parte dos profissionais forenses para que haja uma atuação que seja em consonância com o caráter jurídico-valorativo da Carta Magna. De fato, mostra-se acertada a lição de quem sustenta que

[..] o Direito - mormente o constitucional — não pode ser visto de uma perspectiva isolada da ética-moral, sob pena de formalismo exacerbado e, obviamente, permissividade de, sob este manto, acobertar injustiças. ${ }^{406}$

O que está em jogo é a possibilidade de se interpretar e aplicar o Direito de forma adequada aos novos cenários político-sociais, com vistas à compatibilização entre exigência de segurança jurídica e respostas satisfatórias às demandas emergentes. Em particular, asseverase que os juristas

[...] instigados por uma legislação de novo perfil [...] poderão protagonizar importantes mudanças sócio-políticas por meio do direito, fazendo deste [...] um instrumento transformador de relações sociais superadas e incompatíveis com o mundo atual, caracterizado por conflitos de massa, por reivindicações políticas e por uma crescente organização participativa da sociedade civil. ${ }^{407}$

Em sociedades que ainda não chegaram a se apropriar plenamente dos avanços éticopolíticos conseguidos pela Modernidade, a própria injustiça social torna urgente o enfrentamento da pluridimensionalidade da crise do direito, incumbido, este último, de modificar a realidade em direção à axiologia constitucional. Questões como igualdade, equidade, justiça necessitam de um entendimento crítico por parte do jurista para que ele possa contribuir concretamente para a transformação da realidade social e cumprir aquele mister que lhe é próprio, de modo a satisfazer as expectativas de mudanças que a sociedade civil faz recair sobre ele.

Trata-se de expectativas legítimas, uma vez que a nova ordem constitucional incumbe o operador forense da árdua tarefa de consolidar o Estado Democrático de Direito e uma democracia que salvaguarde a dignidade da pessoa humana por meio da implementação de políticas públicas, inspiradas pelo ideal do bem-estar global da coletividade. Neste sentido, não se pode pensar a interpretação e a aplicação do direito de forma avulsa dos valores constitucionais que, por sua vez, obrigam o profissional forense a entender seu papel em termos de realização de uma sociedade mais justa, ponto de chegada de um trabalho permanente de

\footnotetext{
${ }^{406}$ BEÇAK, Rubens. A Dimensão ético-moral e o direito. Revista Brasileira de Direito Constitucional. n. 09, jan./jun. 2007, p. 307-320.

${ }^{407}$ MACHADO, Antônio Alberto. Ensino jurídico e mudança social. Op. cit., p. 113.
} 
conversão das estruturas sociais, rumo ao atingimento de níveis efetivos de igualdade em todas as esferas.

Mais uma vez, no dizer de Machado

[...] é perfeitamente lícito concluir que os juristas brasileiros, dentro da nova ordem constitucional, passaram a ser os portadores de muitos dos desafios de mudança da realidade social por intermédio do direito, sobretudo a mudança naqueles aspectos que essa realidade se apresenta agudamente injusta e, portanto, incompatível com a ideia de democracia real. ${ }^{408}$

Por isso, deve considerar-se improrrogável o compromisso de colocar o instrumental jurídico a serviço da luta contra a desigualdade, fazendo do exercício da profissão um projeto político consciente e articulado que assegure intervenções públicas concretizadoras.

Em razão da peculiar realidade em que o Direito brasileiro atua, é preciso perguntar pelas formas adequadas de ele se tornar um vetor de transformação das injustiças presentes na sociedade:

[...] o desafio que se nos descortina é: como fazer do direito um vetor de redução de desigualdade e indutor do desenvolvimento? Essa pergunta engendra enormes desafios que, por sua vez, descortinam uma interessantíssima agenda de pesquisa.

Que ferramentas tributárias (como a tributação progressiva), previdenciárias (a ideia de solidariedade contributiva), regulatórias (como as tarifas de serviços públicos universalizantes em termos de acesso e fruição), financeiras (a gestão igualitária da arrecadação e do gasto públicos), sociais (políticas de saúde, educação, moradia, ações afirmativas, entre outras tantas possíveis, podem ser dirigidas a finalidades distributivas com o mínimo de perda de eficiência econômica? ${ }^{409}$

Cabe agora perquirir as potencialidades teóricas disponíveis no cenário da pesquisa atual, tendo em vista o favorecimento de uma avaliação crítica de qual seria o modo mais congruente de o Direito cumprir seu papel no seio de uma sociedade que almeja mudanças e que se percebe separada por um fosso profundo da esfera da ação jurídico-política.

\section{UMA MUDANÇA TRANSICIONAL NO DIREITO BRASILEIRO?}

Ao tentarmos enuclear os rumos do novo pensamento jurídico pátrio, nos deparamos com a ambiguidade de algumas denominações que tentam reunir vertentes, por vezes inconciliáveis, na esteira do debate contemporâneo acerca do próprio Direito. Expressões tais como "Neoconstitucionalismo" e "Pós-positivismo" não passam de designações vazias que exigem um entendimento aprofundado do que realmente algumas tendências teóricas vieram reivindicando nas últimas duas décadas.

\footnotetext{
${ }^{408}$ MACHADO, Antônio Alberto. Ensino jurídico e mudança social. Op. cit., p. 119.

${ }^{409}$ COUTINHO, Diogo R. Desenvolvimento, desigualdade e o papel do direito. Valor Econômico, 2008 , p. E2.
} 
Sendo assim, cabe-nos identificar os marcos diferenciadores desse novo ambiente intelectual e o impacto que ele está tendo na atuação jurídica hodierna.

As referidas tendências parecem ter seu foco na valorização das decisões principiológicas e na vontade de fazer prevalecer, no plano prático, a supremacia constitucional.

Conforme salienta Arruda Alvim,

A preocupação com a efetivação das normas constitucionais, deve-se, à superação do modelo liberal-burguês, oriundo da revolução francesa e, correlatamente ao engrandecimento do papel do juiz nos ordenamento de civil law. [...] Diante da nova consciência do Ocidente em relação ao papel das Constituições [...] os textos constitucionais passaram a ter mais decisiva prática influência na vida social [...]. ${ }^{410}$

Mais especificamente,

[...] o direito constitucional no Brasil passou da desimportância ao apogeu em menos de uma geração. Uma Constituição não é só técnica. Tem de haver, por trás dela, a capacidade de simbolizar conquista e de mobilizar o imaginário das pessoas para novos avanços. ${ }^{411}$

De imediato, constata-se que as mencionadas variantes teóricas convergem no reconhecimento de que o Estado democrático de direito, para ele ser plenamente realizado, exige a superação daquela visão liberal, pautada em prescrições generalistas e fechadas da lei e, por conseguinte, uma adequada compreensão da normatividade dos princípios. Em outras palavras, visa-se à fixação de novos parâmetros na resolução jurídica de conflitos que garantam previsibilidade, mas que sejam, ao mesmo tempo, mais permeáveis às transformações sociais.

A era presente, caracterizada pelo surgimento de direitos e garantias de índole constitucional, torna improrrogável o questionamento dos modos de interpretação e aplicação do Direito para que ele conte não somente com as ferramentas lógico-formais, mas também com o substrato axiológico positivado na Constituição, invocado como verdadeiro norte do exercício jurídico.

É nesse contexto que os princípios ganham um espaço inédito, pois não mais preenchem lacunas na ordem jurídica, mas passam a ser compreendidos como normas. Diversamente dito, a reflexão jurídica pós-positivista volta a incluir a dimensão valorativa no Direito, porém se livrando das categorias metafísicas da tradição ocidental. Dessa supremacia dos princípios

410 ALVIM, Arruda. "Constitucionalismo contemporâneo, jurisdição e mecanismo de controle da discricionariedade judicial". IN: MORAIS da ROSA; et al. Hermenêutica, Constituição, decisão judicial. Estudos em homenagem ao professor Lenio Luiz Streck. Porto Alegre: Livraria do Advogado, 2016, p. 126; 128-129.

411 BARROSO, Luís Roberto. "Neoconstitucionalismo e constitucionalização do direito". Revista da Escola Nacional da Magistratura, vol. I, no 3, 2006, p. 29. 
decorre uma jurisprudência pautada em valores fundantes da vida da coletividade juridicamente organizada:

Princípios não são, como as regras, comandos imediatamente descritivos de condutas específicas, mas sim normas que consagram determinados valores ou indicam fins públicos a serem realizados por diferentes meios. ${ }^{412}$

Sem dúvida, a discussão acadêmica atual tem um foco muito centrado na questão da interpretação do Direito e do papel do operador jurídico no contexto de uma sociedade complexa, caracterizada por uma crescente demanda por justiça social. É neste contexto que veio ganhando destaque a valorização das decisões principiológicas, como modo de rejeição daquela postura teórica, vagamente definida positivista, que é sinônimo de exclusão da dimensão axiológica do Direito e das justificações da ordem moral da argumentação jurídica. Se beneficiando com relevantes contribuições (Dworkin, Alexy, Zagrebelsky, Atienza, Troper, entre outros), o pensamento hodierno preza por uma visão do Direito pautada numa compreensão inovadora dos princípios e da prática argumentativa. Assim, configura-se um cenário problemático, uma vez que se trata de estabelecer de qual forma um sistema jurídico possa se adequar aos valores de um Estado democrático de direito que exige flexibilidade, abertura, mas, ao mesmo tempo, segurança jurídica. Encontrar um ponto de equilíbrio é o grande desafio de quem visa ultrapassar a pura e simples aplicação do Direito em termos de subsunção do fato à norma, para trazer à tona a socialidade da esfera jurídica em que a interpretação e a argumentação desempenham um papel crucial.

O que está em jogo é a possibilidade de se direcionar a ação do Estado rumo aos fins públicos contemplados pela Lei maior que implica numa tradução de valores que, por sua vez, engendram parâmetros para o interprete do Direito, meios de identificação/explicitação de diretrizes vinculantes, à luz das quais a ordem social será objeto de transformação pela implementação de políticas públicas apropriadas.

Fica claro que esta maneira de se colocar o problema da interpretação do Direito se relaciona com a questão da concretização do assim chamado projeto constitucional, isto é, de como realizar aquela sociedade pautada no valor principiológico da dignidade humana em que se condensam as razões para o agir público cujo fim é a plena promoção/proteção da pessoa, sempre tida como fim da atuação jurídico-política. A interpretação principiológica é reinvindicação do caráter instrumental do Direito: o Direito deve voltar a desempenhar seu

412 BARROSO, Luís Roberto. Neoconstitucionalismo e constitucionalização do direito. Revista da Escola Nacional da Magistratura, vol. I, nº 3, 2006, p. 36. 
mister no seio de uma sociedade que o concebe como modo de afirmação de valores fundantes do convívio sócio-político, constitucionalmente estabelecido.

A referida ênfase aos princípios chama a atenção para um modo de interpretação aberto que é a ponderação, em que as razões para decidir são sopesadas de modo a se determinar qual o valor que deve prevalecer, caso haja colisão entre direitos fundamentais:

De modo geral, pode-se dizer que a ponderação de princípios tem uma vinculação a procedimentos tópicos, menos enquanto um procedimento voltado para uma estrutura normativa capaz de bloquear a competência normativa infraconstitucional (controle de constitucionalidade), mais como um modo de pensar a realizabilidade constitucional em vista de um projeto político que se define caso a caso. ${ }^{413}$

A essa altura é compreensível a preocupação de quem pergunta pela segurança jurídica, posto que a norma sempre revela sua contingência conteudística e, por conseguinte, remete para o substrato valorativo que a ela subjaz. Daí a questão da relação entre axiologicidade e juridicidade das normas, tendo em vista o problema da expansão normativa pelo exercício do papel interpretativo do aplicador da lei.

Conforme argumenta Mártin Haeberlin:

O método tópico-sistemático (ou indutivo-científico) parece melhor instruir, de fato a pretenciosa tarefa de realizar ciência na multifacetada realidade jurídica do interesse público. Falta algo a ele, porém, quando se busca o conhecimento no domínio na ética, lugar em que se formam as leis morais e jurídicas, onde o conhecimento não se restringe às qualidades de falso e verdadeiro. Nesse domínio, o falso e o verdadeiro ostentam essa qualidade sempre em relação a algo (uma proposição de fins). ${ }^{414}$

Por conseguinte,

[...] os direitos sociais, produto típico do Estado providência, [...] colocam-se como exigência de implementação. Isso altera o desempenho e a função do judiciário, ao qual, perante eles ou perante a sua violação, não cumpre apenas julgar no sentido de estabelecer o certo e o errado com base na lei [...] mas também e, sobretudo, examinar se o exercício do poder de legislar conduz à concretização dos resultados objetivados [...]. Altera-se, do mesmo modo, a posição do juiz, ao ver-se posto diante de uma corresponsabilidade no sentido de uma exigência de ação corretiva de desvios na consecução das finalidades a serem atingidas por uma política legislativa. Com isso, tal responsabilidade, que pela clássica divisão dos poderes, cabia exclusivamente ao Legislativo e ao Executivo, passa a ser imputada também à Justiça. ${ }^{415}$

413 TERCIO S., Ferraz Junior. "Ponderação de princípios e tópica jurídica".IN: MORAIS da ROSA; et al. Hermenêutica, Constituição, decisão judicial. Estudos em homenagem ao professor Lenio Luiz Streck. Porto Alegre: Livraria do Advogado, 2016, p. 307.

${ }^{414}$ HAEBERLIN. Martin. Uma teoria do interesse público. Porto alegre: Livraria do Advogado, 2017, p. 192.

415 TERCIO S., Ferraz Junior. "Ponderação de princípios e tópica jurídica".IN: MORAIS da ROSA; et al. Hermenêutica, Constituição, decisão judicial. Estudos em homenagem ao professor Lenio Luiz Streck. Op. cit., p. 301-302. 
Em razão da crescente complexificação da sociedade tecnológica, o juiz deixa de ser simples julgador de fatos, compreendidos por via da mera subsunção dos mesmos a uma dada norma vigente, para se tornar realizador de um projeto político que coincide com um modo de atuação que transforma a sociedade.

Nesta seara, é prioritário pensar a execução dos preceitos constitucionais de modo a se evitar que o inteiro aparelho do Estado (jurídico-administrativo) fique desprovido de sua finalidade última.

Em outras palavras:

Por extensão, pode-se dizer que os procedimentos jurídicos de argumentação tópica,
nas sociedades políticas contemporâneas, não visam mais inteiramente àquela
congruência adaptativa de normas constitucionais, mas passam a buscar uma
legitimação social propiciada pela real efetivação dos direitos, em vista de uma
consecução prospectiva. ${ }^{416}$

Tal abordagem consequencialista aponta para a urgência de ir além do legalismo para se favorecer uma aplicação direta dos princípios que agora passam a funcionar como autênticos vetores da ação estatal e que impõem aos operadores do Direito um novo viés interpretativo, mais preocupado com as repercussões futuras decorrentes das decisões tomadas em relação a casos específicos. Hoje o intérprete do Direito é chamado a optar entre uma postura deontológica e uma teleológica: decidir entre o juridicamente correto e o que responde às expectativas de justiça socialmente compartilhada em virtude da qual a própria atuação jurídica se reapropria de sua função no seio da coletividade jurídico e politicamente organizada.

Conforme salientado por outro autor,

\begin{abstract}
A recomendação doutrinária enfatizada aos juízes, acompanhada aos valores que presidem nos dias correntes a aplicação do direito, é a de que procedam à perquirição do valor de justiça, subjacente às normas (ainda que em relação às normas minuciosas isso compreensivelmente se faça em menor escala) e, em aplicando-as haverão de realizar esse valor. [...]. Entre outros aspectos, a função jurisdicional é ampliada para comportar a análise do alcance e significado dos conceitos jurídicos indeterminados, a afetivação das normas constitucionais [...] bem como o controle de validade e eficácia das normas jurídicas em geral. ${ }^{417}$
\end{abstract}

Pode-se afirmar que, em decorrência do reconhecimento da supremacia constitucional sobre as normas jurídicas, surgem novos princípios e critérios hermenêuticos que viabilizam

\footnotetext{
416 Ibid., p. 310.

417, ARRUDA, Alvim. "Constitucionalismo contemporâneo, jurisdição e mecanismo de controle da discricionariedade judicial". IN: MORAIS da ROSA; et al. Hermenêutica, Constituição, decisão judicial. Estudos em homenagem ao professor Lenio Luiz Streck. Op. cit., p. 131.
} 
inéditas formas de controle e de efetivação das normas jurídicas, interpretadas à luz dos preceitos contidos na Carta Magna. Tudo isso representa uma superação do paradigma liberalburguês que ignorava a função propriamente social do direito.

\section{ENTENDENDO OS NOVOS RUMOS DO DIREITO}

Diante das problemáticas anteriormente enfrentadas, cabe constar a insuficiência do paradigma cientificista cuja peculiaridade é o mito da neutralidade da abordagem jurídica e a convicção de que o sistema normativo é capaz de abarcar a totalidade dos fatos sociais. Desta forma, coloca-se a questão da autonomia e da legitimidade do Direito, além do fundamento epistemológico da ciência jurídica.

Nas palavras de Antônio Alberto Machado,

[...] o futuro do direito parece se projetar mesmo na direção de uma dimensão pública e transindividual. A emergência em profusão dos direitos difusos, coletivos e sociais no final do século XX e início do século XXI é a prova mais evidente de que o direito [...] caminha hoje, a passos largos, para a sua decidida publicização. ${ }^{418}$

Frente à consciência de que o fenômeno jurídico é multifacetado e que envolve dimensões transindividuais, torna-se necessário refletir sobre a interdisciplinaridade do próprio conhecimento jurídico, de modo a se favorecer um desenvolvimento crítico-reflexivo do operador jurídico. Na época da globalização da cidadania e dos direitos é preciso se abrir a novos horizontes hermenêuticos que possibilitem a construção de uma sociedade democrática disposta a proteger/promover seus valores universalmente reconhecidos.

Ademais, o Direito precisar elaborar um novo e adequado instrumental teórico e racional para poder dar conta dos direitos fundamentais numa época marcada pelo relativismo aléticoaxiológico que descredencia qualquer discurso que pretenda ser inconteste em relação à realidade humana.

Hoje, o jurista não tem como fugir do papel concretizador dos valores constitucionais e cabe a ele dizer de que forma as conquistas levadas a cabo pela Modernidade - mormente a ideia de dignidade humana - podem ser preservadas mesmo num tempo em que a humanidade parece desprovida de um referencial comum que permita concordar a respeito do certo e do errado.

${ }^{418}$ MACHADO, Antônio Alberto. Ensino jurídico e mudança social. Op. cit., p. 110. 
Antes de mais nada, precisamos perguntar pelo sentido da afirmação de que o Direito deve voltar a se ligar ao universo valorativo de uma dada sociedade e que ele precisa atuar visando transformar a vida coletiva globalmente considerada.

Será que se trata de compreender a esfera normativa "na perspectiva emancipatória de um direito comprometido com as questões fundamentais da política?". 419

Conforme explica Barroso,

O debate, na sua essência, é universal e gravita em torno das tensões e superposições entre constitucionalismo e democracia. É bem de ver, no entanto, que a ideia de democracia não se resume ao princípio majoritário, ao governo da maioria. Há outros princípios a serem preservados e há direitos da minoria a serem respeitados. Cidadão é diferente de eleitor; governo do povo não é governo do eleitorado. No geral, o processo político majoritário se move por interesses, ao passo que a lógica democrática se inspira em valores. E, muitas vezes, só restará o Judiciário para preservá-los. $^{420}$

E Sarmento comenta incisivamente esta nova situação de fato:

[...] a ascensão institucional do Judiciário e a riqueza e importância prática ou simbólica dos temas que ele vem julgando tem provocado um grande aumento no interesse da sociedade pelo Direito Constitucional e pela atuação do Supremo Tribunal Federal. ${ }^{421}$

A este respeito, é de salientar o importante papel democrático que a jurisdição constitucional veio exercendo no Brasil nestes últimos anos e que representa uma relevante contribuição em termos de avanço social do País.

Mais uma vez é a reflexão de Barroso que nos estimula:

Por evidente, no desempenho de tal atribuição, o juiz constitucional não está autorizado a impor suas próprias convicções. Pautado pelo material jurídico relevante (normas, doutrinas, precedentes), pelos princípios constitucionais e pelos valores civilizatórios, cabe-lhe interpretar o sentimento social, o espírito de seu tempo e o sentido da história. Com a dose de prudência e de ousadia. ${ }^{422}$

A própria expansão da jurisdição constitucional é fruto da exigência improrrogável de se preservar as condições de legitimidade do Estado democrático de direito, pautado nos valores

\footnotetext{
419 Ibid., p. 111.

420 BARROSO, Luís Roberto. Neoconstitucionalismo e constitucionalização do direito. Revista da Escola Nacional da Magistratura, vol. I, nº 3, 2006, p. 70.

421 SARMENTO, Daniel. "O neoconstitucionalismo no Brasil: riscos e possibilidades". In: LEITE, George Salomão; SARLET, Ingo Wolfgang (orgs.). Direitos fundamentais e estado constitucional. Coimbra: Coimbra Editora, p. 19, 2009.

${ }^{422}$ BARROSO, Luís Roberto. "A função representativa e majoritária das cortes constitucionais". IN: MORAIS da ROSA; et al. Hermenêutica, Constituição, decisão judicial. Estudos em homenagem ao professor Lenio Luiz Streck. Op. cit., p. 175.
} 
constitucionais que possuem força normativa e desempenham a função direcionadora da atividade administrativa pública e definem os fins do próprio convívio jurídico-político. A primazia da Constituição e o mister do STF - em termos de interpretação final vinculante - se justificam à luz da necessidade de desempenhar uma adequada função de controle dos atos administrativos para que seja garantida a proteção dos direitos fundamentais e o bom funcionamento da democracia quanto ao modo de autodeterminação de um povo que compartilha um senso de justiça, positivado na Carta Magna.

A referida questão remete diretamente para a assim chamada crise da representação política que é crise dos parlamentos no que diz respeito à dificuldade de eles serem expressão autêntica da vontade majoritária da população.

No Brasil [...] vive-se uma situação delicada, em que a atividade política desprendeuse da sociedade civil, que passou a vê-la com indiferença, desconfiança ou desprezo. [...]. Em curioso paradoxo, o fato é que em muitas situações juízes e tribunais se tornaram mais representativos dos anseios e demandas sociais do que as instâncias políticas tradicionais. ${ }^{423}$

Trata-se do reconhecimento de que a legitimidade do governo majoritário não deriva da simples eleição, uma vez que ele precisa passar por um processo constante de sintonização com os fins que o Constituinte confiou aos agentes públicos, no respeitante à razão de ser do aparelho jurídico-político-administrativo.

Contudo, será que existe um conflito real entre jurisdição constitucional e democracia? Pode a Suprema corte anular decisões políticas legitimamente tomadas? E em virtude de quais princípios?

Em primeiro lugar, a política majoritária não é sinonímica de representatividade plena da população e isso se deve ao caráter dinâmico da democracia que visa a razões válidas para todos os processos decisórios. Uma democracia madura não tem como fugir do problema do debate público como condição de apreciação de razões que possam ser compartilhadas por sujeitos racionais que fazem da liberdade de autodeterminação um valor inviolável e norteador da construção do Estado constitucional. Neste sentido, a Corte constitucional desenvolve razões para a decisão, acaba institucionalizando o exercício da razão prática no âmbito da argumentação jurídica.

Vale a pena observar que

Se, pois, no passado, (quando apareceram os direitos fundamentais sociais, chamados de segunda geração) a argumentação jurídica dirigia-se a postular uma intervenção na

${ }^{423}$ Ibid., p. 166. 
forma de uma prestação garantidora (prestação jurisdicional: direito de ação judicial e tutela judicial), agora uma argumentação legitimadora mediante princípios até começa com uma prestação de garantia (direito à previdência, direito à saúde) mas avança para direitos a prestações capazes de não apenas proteger os desiguais em face dos iguais, mas de promover entre ambos uma igualdade, não apenas com olhos para um antecedente [...]. É perante esse problema de como institucionalizar socialmente no ambiente extraoficial (na escola, no hospital, na fábrica na empresa) não um direito, desde o passado, de ser tratado igualmente apesar das desigualdades, mas de promover uma igualdade onde existam desigualdades, que a tópica jurídica como lugares comuns exerce uma função legitimadora prospectiva (em vista do futuro). ${ }^{424}$

Face a essa discrepância entre

[..] a proclamação formal dos direitos [...] e o real estatuto político dos indivíduos e dos grupos, com suas diferenças, estende-se um vasto espaço ocupado por formas de tensão política, a exigir da jurisdição uma função legitimadora e não propriamente validadora [...]. Por extensão, pode-se dizer que os procedimentos jurídicos de argumentação tópica, nas sociedades políticas contemporâneas, não visam mais inteiramente àquela congruência adaptativa de normas constitucionais, mas passam a buscar uma legitimação social propiciada pela real efetivação dos direitos em vista de uma consecução prospectiva. ${ }^{425}$

Essa sociedade política in progress exige formas de atuação jurídica voltadas para a concretização da vontade constitucional em termos de construção de uma sociedade justa e livre em que o valor principiológico da dignidade humana define tarefas e fins da ação estatal e adquire a configuração de medidor de constitucionalidade. A democracia constitucional consta de dinâmicas transformadoras da vida sócio-política e tem na livre argumentação dos participantes o modo natural de apropriação/explicitação de seu alicerce.

Por conseguinte, o Direito necessita voltar à sua função originária, a de preservador/promovedor/concretizador de valores vinculantes para todos e positivados no Pacto ético fundante, fonte legitimadora da atividade do Estado e de suas intervenções na vida dos cidadãos.

\section{CONSIDERAÇÕES FINAIS}

Neste estudo, tem se tentado apresentar a incidência das novas orientações do pensamento jurídico, tendo em vista a urgência de se ultrapassar estéreis controvérsias que envolvem os intelectuais da área, para se favorecer uma maior concentração sobre o cerne da

${ }^{424}$ TERCIO S., Ferraz Junior. "Ponderação de princípios e tópica jurídica".IN: MORAIS da ROSA; et al. Hermenêutica, Constituição, decisão judicial. Estudos em homenagem ao professor Lenio Luiz Streck. Op. cit., p. $310 ; 311$.

425 Ibid., p. 310. 
questão, isto é, a redescoberta da natureza do Direito no seio de uma sociedade política que faz da liberdade, da justiça e da igualdade os vetores da transformação de seu convívio.

Neste sentido, tem sido necessário abordar o problema da reaproximação entre direito e moral à luz da urgência da implementação da axiologia constitucional, fonte legitimadora da atuação estatal e jurídica. Um Direito mais sensível às transformações sociais e que saiba proporcionar razões para o próprio agir de forma a garantir a aceitabilidade de decisões tomadas em nome da coletividade e cuja finalidade é a consecução de um interesse jurídico-social constitucionalmente estabelecido.

Aqui dá-se a crucialidade da relação aparentemente conflituosa entre democracia e jurisdição constitucional: a exigência de se corrigir o jogo da autodeterminação de um povo torna necessário o exercício do papel representativo do STF que, em virtude de sua competência interpretativa do texto constitucional, garante o funcionamento legítimo da democracia, uma vez que a simples investiduras dos representantes políticos é somente uma condição necessária, porém não suficiente para que haja efetiva representação do povo o qual, por sua vez, precisa reconhecer na atividade político-administrativa do Estado o modo de implementação mais adequado dos direitos fundamentais.

\section{REFERÊNCIAS}

ALEXY, Robert. Teoria dos direitos fundamentais. Tradução Luis Virgilio A. Silva. São Paulo: Malheiros, 2008.

ALVIM, Arruda. "Constitucionalismo contemporâneo, jurisdição e mecanismo de controle da discricionariedade judicial". IN: MORAIS da ROSA; et al. Hermenêutica, Constituiçãa, decisão judicial. Estudos em homenagem ao professor Lenio Luiz Streck. Porto Alegre: Livraria do Advogado, 2016.

ÁVILA, Umberto. Teoria dos princípios. 9. ed. São Paulo: Malheiros, 2009.

BARROSO, Luís Roberto. "Neoconstitucionalismoe constitucionalização do direito". Revista da Escola Nacional da Magistratura, vol. I, n 3, 2006,

BARROSO, Luís Roberto; BARCELLOS, Ana Paula de. "O começo da história: a nova interpretação constitucional e o papel dos princípios no direito brasileiro". In: BARROSO, Luís 
Roberto. A nova interpretação constitucional: ponderação, direitos fundamentais e relações privadas. Rio de Janeiro: Renovar, 2003.

BEÇAK, Rubens. A Dimensão ético-moral e o direito. Revista Brasileira de Direito Constitucional. n. 09, jan./jun. 2007.

CASTANHEIRA NEVES, António. Digesta: escritos acerca do direito, do pensamento jurídico, da sua metodologia e outros. Coimbra, Coimbra, 2008. v. 3.

CARBONELL, Miguel (Org.). Neoconstitucionalismo(s). Madrid: Trotta, 2003.

COUTINHO, Diogo R. Desenvolvimento, desigualdade e o papel do direito. Valor Econômico, 2008, E2, v. 4.

DIMOULIS, Dimitri. "Neoconstitucionalismo e moralismo jurídico". In: SARMENTO, Daniel (Org.). Filosofia e teoria constitucional contemporânea. Rio de Janeiro: Lumen Juris, 2009.

FREITAS, Juarez. Direito fundamental à boa administração pública. 3 ed. São Paulo, 2007.

HAEBERLIN. Martin. Uma teoria do interesse público. Porto alegre: Livraria do Advogado, 2017.

KELSEN, Hans. Teoria Pura do Direito. 3. ed. São Paulo: Martins Fontes, 1991.

MACHADO, Antônio Alberto. Ensino jurídico e mudança social. 2 Ed. São Paulo: Atlas, 2008 .

NADER, Paulo. Introdução à Ciência do Direito. $29^{\mathrm{a}}$ ed. Rio de Janeiro: Freitas Bastos, 1989

SARMENTO, Daniel. "O neoconstitucionalismo no Brasil: riscos e possibilidades". In: LEITE, George Salomão; SARLET, Ingo Wolfgang (orgs.). Direitos fundamentais e estado constitucional. Coimbra: Coimbra Editora, 2009.

STRECK, Lenio Luiz. Jurisdição Constitucional e Hermenêutica: Perspectivas $e$ Possibilidades de Concretização dos Direitos Fundamentais-Sociais no Brasil. Novos Estudos Jurídicos, v. 8, II, 2003. 
2011.

Hermenêutica Jurídica e(m) crise. $10^{\text {a }}$ ed. Porto Alegre: Livraria do Advogado,

Verdade e Consenso. 4.ed. São Paulo: Saraiva, 2011.

TERCIO S., Ferraz Junior. "Ponderação de princípios e tópica jurídica".IN: MORAIS da ROSA; et al. Hermenêutica, Constituição, decisão judicial. Estudos em homenagem ao professor Lenio Luiz Streck. Porto Alegre: Livraria do Advogado, 2016.

\title{
JUDICIAL PRACTICE AND PARADIGM SHIFT
}

\begin{abstract}
In the following pages, we aim at facing the matter of the judicial practice within a complex society in costant transformation, whose normative strength of its Constitution is challenged by inequalities and uneffectiviness of basic rights. If, from one hand, the legal professional is not dispensed from knowing law and aplication rules, from the other hand we need to think of concrete ways of habilitating the legal professional of tomorrow in terms of a practice able to deal with challenges coming from an extremely conflicting world. In this respect, the objetive is favouring the development of a critical conscience, so that the legal operator can satisfy the yearning for justice of the social environment where he works.
\end{abstract}

Keywords: Constitution. Judicial practice. Society. Juridical science. 